\title{
Comparison of estimates of feed energy obtained from ostriches with estimates obtained from pigs, poultry and ruminants
}

\author{
T.S. Brand ${ }^{1}$, J.P. van der Merwe ${ }^{1}$, M. Salih ${ }^{2}$ and Z. Brand ${ }^{3}$ \\ ${ }^{1}$ Elsenburg Agricultural Research Centre, P Bag X1, Elsenburg, 7607; ${ }^{2}$ Ankara University, Ankara 06110, Ankara, Turkey \\ ${ }^{3}$ Klein Karoo Agricultural Development Centre, PO Box 313, Oudtshoorn, 6620
}

\section{Introduction}

Energy values for feed raw materials for ostriches are scarce. The determination of the energy content of feedstuffs for ostriches by a conventional metabolism study requires a large quantity of feed, many animals, is time consuming, expensive and very difficult to conduct with these semi-wild animals. Cilliers (1994) therefore, tested a range of raw materials for ostrich metabolizable energy (ME) contents, and also determined the energy contents of the same materials with poultry. He used these values in a linear model for calculating energy values for ostriches from available poultry values. This study was conducted to compare the ostrich ME values of a range of balanced diets different in fibre content, and therefore also different in energy content, with energy values obtained from pigs, poultry as well as ruminants (based on in vitro methods).

\section{Materials and Methods}

Nine balanced ostrich diets differing in fibre content were used. The ME contents of the diets were determined for ostriches (Cilliers, 1994), poultry (McNab, 1990) and pigs (Kemm \& Ras, 1971). The in vitro digestible organic matter (DOM) content of the diets was also determined (Tilley \& Terry, 1963) and values converted to ruminant ME values as described by Van der Honing \& Alderman (1988).

\section{Results and discussion}

Table 1 Metabolizable energy content of diets as determined in ostriches, pigs, poultry and ruminants (values for ruminants are from in vitro analyses).

\begin{tabular}{lcccc}
\hline Diet & $\begin{array}{c}\text { Ostrich } \\
(\mathrm{TME}, \mathrm{MJ} / \mathrm{kg})\end{array}$ & $\begin{array}{c}\text { Pig } \\
(\mathrm{ME}, \mathrm{MJ} / \mathrm{kg})\end{array}$ & $\begin{array}{c}\text { Poultry } \\
(\mathrm{TME}, \mathrm{MJ} / \mathrm{kg})\end{array}$ & $\begin{array}{c}\text { Ruminant } \\
(\mathrm{ME}, \mathrm{MJ} / \mathrm{kg})\end{array}$ \\
\hline Low fibre: & & & & \\
$\quad$ Starter & 4.98 & 12.84 & 16.80 & 13.19 \\
Grower & 14.76 & 12.26 & 14.70 & 12.58 \\
Finisher & 14.88 & 13.02 & 14.10 & 12.27 \\
Medium fibre: & & & & \\
Starter & 14.08 & 10.36 & 12.30 & 11.35 \\
Grower & 13.99 & 10.39 & 9.70 & 10.14 \\
Finisher & 13.94 & 11.08 & 12.20 & 10.93 \\
& & & & \\
High fibre: & & & & \\
Starter & 11.96 & 9.79 & 8.70 & 9.99 \\
Grower & 12.80 & 8.82 & 8.20 & 9.58 \\
Finisher & 12.44 & 10.45 & 9.00 & 10.25 \\
\hline
\end{tabular}

Ostriches had significantly $(\mathrm{P} \leq 0.01)$ higher ME values than both pigs and ruminants for all three types of diets (low fibre, medium fibre as well as high fibre). There was no significant difference between the ME values for ostriches and poultry with the low fibre diet (high concentrate diet). ME values for ostriches, however, were higher than for poultry for both the medium and high fibre diets. This is related to the ability of ostrich to digest fibre. Swart (1988) also showed that ostriches effectively digest plant fibre, and more specifically hemicellulose (66\%) and cellulose (38\%). Equations derived from linear regression analyses of the ME values determined using the different animal species may be useful for predicting ME values of feedstuffs for ostriches: 
Short paper and poster abstracts: $38^{\text {th }}$ Congress of the South African Society of Animal Science TME ostrich $(\mathrm{MJ} / \mathrm{kg})=9.936+0.326 \times \mathrm{TME}$ poultry $\left(\mathrm{P} \leq 0.01 ; \mathrm{R}^{2}=79.6 ;\right.$ SE $\left.\mathrm{xy}=0.54\right)$

TME ostrich $(\mathrm{MJ} / \mathrm{kg})=6.743+0.638 \times \mathrm{ME}$ pig $\left(\mathrm{P} \leq 0.01 ; \mathrm{R}^{2}=67.7 \% ; \mathrm{SE} \mathrm{xy}=0.67\right)$

TME ostrich $(\mathrm{MJ} / \mathrm{kg})=5.940+0.706 \mathrm{x}$ ME ruminant $\left(\mathrm{P} \leq 0.01 ; \mathrm{R}^{2}=69.24 \% ; \mathrm{SE} \mathrm{xy}=0.66\right)$

\section{Conclusion}

It is evident that ostriches maintained higher ME values than poultry, pigs as well as ruminants when consuming high fibre diets. ME values from all three of these species may be used to predict ME values for ostriches.

\section{Acknowledgements}

Klein Karoo Cooperation is acknowledged for financial support of the study.

\section{References}

Cilliers, S.C., 1994. Ph.D. Thesis. University of Stellenbosch, Stellenbosch.

Kemm, E.H. \& Ras, M.N., 1971. S. Afr. J. Anim. Sci. 1, 9.

McNab, J.M., 1990. Feedstuffs Evaluation. Butterworths, London.

Statistical Graphics, 1991. Statistical Graphics Inc, Rockville, MD, USA.

Swart, D., 1988. Ph.D. Thesis, University of Stellenbosch, Stellenbosch.

Tilley, J.M.A. \& Terry, R.A., 1963. J. Br. Grassld. Soc. 18, 101.

Van der Honing, Y. \& Alderman, G., 1988. Livest. Prod. Sci. 19, 217. 